\title{
Fabrication of Spherical Silica Particles from Sodium Silicate and Their Application as Support Materials for Ruthenium-based Catalysts for the Hydrogenation of Supercritical Carbon Dioxide into Formic Acid
}

\author{
Tetsuo UmeGAKI ${ }^{\dagger}$, Yuta EnOmoto, and Yoshiyuki KoJima \\ (Received February 17, 2017)
}

\begin{abstract}
Spherical silica nanoparticles were fabricated from sodium metasilicate solution using urea as a precipitant. Homogeneity of the silica particles was improved by adjusting the ratio of sodium metasilicate to urea, and their size was adjusted between 20 and $1600 \mathrm{~nm}$ by adjusting the amount of sodium metasilicate and urea. Supported ruthenium catalysts were prepared by impregnation method using the silica spheres as a support of the catalysts. The amount of supported ruthenium depended on the ruthenium concentration during the impregnation process. The catalytic activity for hydrogenation of carbon dioxide into formic acid increased with increasing their ruthenium contents. The activity did not significantly depend on the particle size of the silica supports; however, the amount of ruthenium deposited on the particles depended on the particle size of the silica supports, with a larger amount of ruthenium being immobilized on the silica supports with a smaller particle size.

本研究では, ルテニウム系触媒の担体として, メタケイ酸ナトリウムを原料とし, 尿素を沈殿剂とした方法で球状シリカ粒子の調製 を試みた。シリカ粒子の均一性は, メ夕ケイ酸ナトリウムと尿素の比率により調整可能であり, そのサイズは $20 １ 600 \mathrm{~nm}$ まで調整 可能であることが確認された。ルテニウム担持触媒はこれらのシリカ粒子を担体として含浸法により調製したところ，ルテニウム溶液 の濃度により担持されるルテニウム量が変化し, そのルテニウム量によって二酸化炭素水素化からのギ酸合成活性が変化することが 確認された。一方，担持されるルテニウム量はシリカ担体の粒径が小さいほど増大するが，活性にはそれほど影響しないことが確認 された。
\end{abstract}

Key Words

Spherical silica particles, Sodium metasilicate, Supported ruthenium catalyst,

Hydrogenation of carbon dioxide into formic acid

\section{Introduction}

Silica nanoparticles are generally synthesized by tetraethyl orthosilicate (TEOS) as a precursor in alkaline medium ${ }^{1)}$. Spherical, non-agglomerated silica nanoparticles are usually produced by this method ${ }^{2)}{ }^{3)}$, and their particle size increases upon increasing the concentration of both TEOS and ammonia ${ }^{4}$. In addition to TEOS, sodium silicate solution is another low-cost precursor which is used for the synthesis of silica nanoparticles. Sodium silicate solution offers several advantages over TEOS, including its ability to form nanoparticles of uniform size in high yields ${ }^{5)}$. The

College of Science and Technology, Nihon University 1-8-14, Kanda Surugadai, Chiyoda-ku, Tokyo 101-8308, Japan

$\dagger \quad$ Corresponding author: umegaki.tetsuo@nihon-u.ac.jp conventional synthesis of silica from sodium silicate solution is usually performed in acid medium ${ }^{6)}{ }^{7)}$, which can often result in agglomeration of the particles ${ }^{2}$. However, the use of alkaline sodium silicate solutions as precursors for nonagglomerated silica nanoparticles has been less studied. The production of metal oxide particles via homogeneous precipitation with urea has been demonstrated as a promising approach to the successful preparation of powders with controlled particle size and shape ${ }^{8) \sim 10)}$.

On heating the aqueous solution of urea $\left(\mathrm{NH}_{2}\right)_{2} \mathrm{CO}$, urea was decomposed via hydrolysis. During the decomposition of urea, $\mathrm{NH}_{4}{ }^{+}$ions are slowly produced homogeneously throughout the solution, avoiding the formation of localized $\mathrm{H}^{+}$gradients. Thus, in contrast to 
heterogeneous precipitation with alkali or ammonia, when ureic solutions are applied to the hydrolysis of metal ions the precipitating agent is slowly formed throughout the reaction mixture allowing the slow ripening of particles, resulting in better product crystallinity and uniformity. According to the Arrhenius plot for the decomposition urea, its activation energy is $32.4 \mathrm{kcal} \mathrm{mol}^{-1}{ }^{10}$, and this decomposition can be precisely controlled using the heating temperature. The decomposition constant of urea in water at $298 \mathrm{~K}$ is calculated to be $6.65 \times 10^{-8} \mathrm{~s}^{-1}$, which is $\sim 1 / 15000$ of its value at $363 \mathrm{~K}$. Thus, urea is neither acidic nor alkaline in water under ambient conditions. However, it produces ammonia in water upon heating, which causes the solution to become alkaline. A urea solution at high temperature can dissolve silica in a controlled manner even though silica is sparingly soluble in water ${ }^{11) \sim 21}$, and the weak alkalinity of the urea solution allows it to be used for the uniform deposition of metal precursors.

Using spherical silica particles as a support, we prepared supported catalysts for the hydrogenation of carbon dioxide. Carbon dioxide is an attractive carbon resource to reduce carbon wastes from various industries ${ }^{22) ~} \sim 24$, and the hydrogenation of carbon dioxide to formic acid $\left(\mathrm{H}_{2}+\right.$ $\mathrm{CO}_{2} \rightarrow \mathrm{HCO}_{2} \mathrm{H}$ ) has been studied from this view point ${ }^{25)} \sim 27$ ) Waste gas of fossil fuels directly converts to useful products in this process, and it is also expected as a potential route for hydrogen storage. Homogeneous metal complex catalysts ( $\mathrm{Ru}, \mathrm{Pd}$, etc.) have been developed for the hydrogenation reaction for some decades, and significant development in catalyst activity has been achieved ${ }^{25)} \sim 27$ ). Gas phase hydrogenation is thermodynamically unfavorable ${ }^{28)}$, however, the equilibrium was shifted in favor of product formation under high pressures ${ }^{29}$. Under supercritical conditions, the turnover frequency of the reaction increases with increasing the partial pressure of carbon dioxide ${ }^{30}$. The catalytic reaction have typically been tested with $\mathrm{H}_{2} / \mathrm{CO}_{2}=5 / 8(\mathrm{MPa} / \mathrm{MPa})$, at lower total pressure with the same reactant ratio ${ }^{28}{ }^{31}{ }^{32}$. Although the reasonable conversions and yields of formic acid have been obtained using homogeneous catalysts, the separation of formic acid from the bases and catalysts remains a challenge. Thus, a heterogeneous catalytic system is required to develop. To the best of our knowledge, very few heterogeneous systems with solid (supported) catalysts have been investigated in this reaction ${ }^{28)}$ 33) $\sim 37$ ).

In the present study, we have investigated the preparation of spherical silica particles using urea, and apply them as supports for ruthenium-based catalysts for the hydrogenation of supercritical carbon dioxide into formic acid.

\section{Experimental}

\subsection{Sample preparation}

Spherical silica particles were prepared using a sodium metasilicate solution $\left(\mathrm{SiO}_{2} 35-38 \%, \mathrm{Na}_{2} \mathrm{O}\right.$ 17-19 \%) and urea under hydrothermal conditions. All reagents were commercially purchased and used without purification. Sodium metasilicate solution (0.24 - $5.0 \mathrm{~g})$ and urea (0.3 - $2.4 \mathrm{~g})$ were dissolved in deionized water $(15 \mathrm{~mL})$ in a Teflon-lined stainless steel vessel, and the solution was heated at $393 \mathrm{~K}$ for $15 \mathrm{~h}$. The suspension was filtered and washed using deionized water, and the powder product was obtained after drying.

Using these spherical silica particles as supports, supported ruthenium catalysts were prepared. The silica particles $(0.384 \mathrm{~g})$ were immersed in $10 \mathrm{~mL}$ of aqueous solution of ruthenium chloride n-hydrate $(\mathrm{n} \approx 1.87$ ) with 28 wt.\% of aqueous ammonia solution ( $5 \mathrm{~mL}$ ). The concentration of ruthenium species was adjusted from $2.0 \times 10^{-4}-8.0 \times 10^{-4}$ $\mathrm{M}$. The suspension was filtered and washed using deionized water, and the powder product was obtained after drying.

\subsection{Characterization}

The morphologies of the silica supports and the catalysts were observed using a Hitachi S-450 scanning electron microscope (SEM) (acceleration voltage of $15 \mathrm{kV}$ ), and a Hitachi FE2000 transmission electron microscope (TEM) (acceleration voltage of $200 \mathrm{kV}$ ). The Fourier transform infrared spectroscopy (FTIR) spectra of the samples were recorded using an FTIR-8400S spectrophotometer (Shimadzu Co. Ltd.) at a resolution of $4 \mathrm{~cm}^{-1}$. X-ray photoelectron spectra (XPS) was performed using an ESCA-3400 spectrometer (Shimadzu Co. Ltd.) equipped with a MgKa X-ray source (1253.6 eV) operating at $10 \mathrm{kV}$ and $10 \mathrm{~mA}$. The binding energies (BE) were corrected by reference to the $\mathrm{C} 1 \mathrm{~s}$ peak at $285.0 \mathrm{eV}$.

\subsection{Catalytic activity}

Hydrogenation of carbon dioxide was carried out in a 120-mL stainless steel autoclave with a magnetic stirrer (Taiatsu Techno). Triethylamine (4 mL) and deionized water $(2 \mathrm{~mL})$ were added to the supported ruthenium catalyst suspension including $2 \mathrm{~g}$ of the catalyst. The autoclave was heated to $353 \mathrm{~K}$. The reactor was then pressurized to $5 \mathrm{MPa}$ with $\mathrm{H}_{2}$, and carbon dioxide was introduced from a cooled $(268 \mathrm{~K})$ reservoir using a high pressure liquid chromatography pump until the total pressure was increased to $13.0 \mathrm{MPa}$. After the reaction for $3 \mathrm{~h}$, the liquid mixture from the autoclave was analyzed with a Shimadzu GC 8A gas chromatograph equipped with a 15\% TSG-1 on SHINCARBON A column (Shimadzu, $2 \mathrm{~m} \times 3 \mathrm{~mm}$ ) and a 
thermal conductivity detector, and the turnover number (TON) of formic acid, which is the number of moles of formic acid produced per mole of ruthenium, was calculated.

\section{Results and discussion}

We investigated the effect of the amount of urea on the morphology of silica particles. Fig. 1 shows SEM images of silica particles prepared using different amount of urea, and clearly indicates that the morphology depends on the amount of urea used. When $0.6 \mathrm{~g}$ of urea is used, the sample consists of micro-sized rock-like particles (Fig. 1(a)), indicating that the amount of urea is insufficient to react completely with the sodium metasilicate, and unreacted sodium metasilicate precipitates after drying the resulting sample. Conversely, when 1.2 and $2.4 \mathrm{~g}$ of urea are used, the resulting samples consist of spherical particles with a diameter of $\sim 1600 \mathrm{~nm}$ (Fig. 1(b), (c)), indicating that 1.2 and $2.4 \mathrm{~g}$ of urea is sufficient to completely react with the sodium silicate and produce homogeneous particles. In addition, the results of energy-dispersive X-ray spectroscopy (EDX) and XPS reveal that the main components of the particles are silicon and oxygen, indicating that the particles mainly contain silica. We also investigated the effect of amount of sodium metasilicate and urea on morphology of silica particles.

We also investigated the effect of the amount of sodium metasilicate and urea on the morphology of the silica particles. Based on the result shown in Fig. 1, a constant molar ratio of urea to sodium silicate (1.2 $\mathrm{g}$ of urea / $5.0 \mathrm{~g}$ of sodium metasilicate) was used. Fig. 2 shows SEM images of samples prepared with different amounts of sodium metasilicate and urea, and in the inset of Fig. 2(a), the TEM image of the sample is shown. All the samples contain spherical particles, and the particle size depends on the amounts of reagents used. The particle size increases from $\sim 20$ to $\sim 1600 \mathrm{~nm}$ upon increasing the amount of sodium metasilicate and urea, indicating that the concentration of sodium metasilicate and urea significantly influence the silica particle size. Fig. 3 shows relationship between sodium metasilicate concentration and the average particle size. The particle size increases parabolically with increasing sodium metasilicate concentration, indicating that the particle size increases via the aggregation of smaller particles. The tendency reflected their specific surface area, and the surface area of the spherical silica particles prepared with the amount of sodium silicate $=1$, 2, 3, 4, and $5 \mathrm{~g}$ was 45.3, 15.2, 5.2, 2.2, $3.6 \mathrm{~m}^{2} \mathrm{~g}^{-1}$, respectively. The results indicate that the specific surface area of the spherical silica particles decrease with increasing their particle size. Explosive nucleation can be achieved at a relative high temperature, usually at temperatures higher than $356 \mathrm{~K}^{\left.38{ }^{39}\right)}$. In the present study, we prepared spherical silica particles over the temperature, thus it is possible that the primary particles of the silica particles homogeneously formed and aggregated to form larger particles.

Using the silica particles as supports for rutheniumbased catalyst, we investigated catalysts prepared by the impregnation method. The morphology of the supported catalysts does not significantly change after impregnation with ruthenium species. Fig. 4 shows XPS spectra of ruthenium species on the spherical silica particles. Samples of spherical silica particles with a diameter of $\sim 1600 \mathrm{~nm}$ was used. The peak assigned to $\mathrm{Ru}^{3+}$ species at $283.3 \mathrm{eV}$ is shown in Fig. 4(a), indicating that the surface ruthenium species is $\mathrm{Ru}(\mathrm{OH})_{3}{ }^{39)}$. It was also confirmed that there was no significant peak shift assigned to active ruthenium species after hydrogenation of carbon dioxide shown as in Fig. 4(b). Fig. 5 shows the influence of the ruthenium
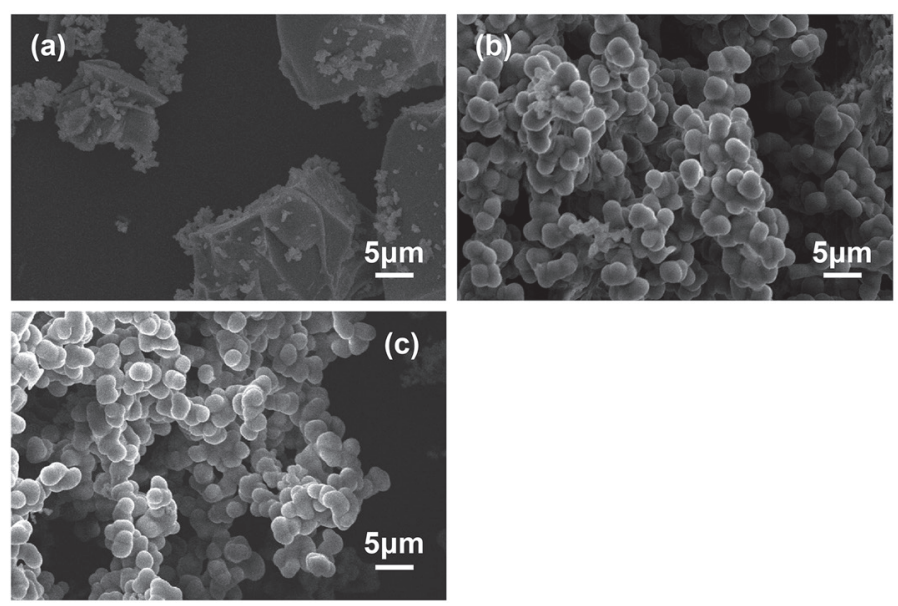

Fig. 1 Influence of the amount of urea on the morphology of silica particles. Amount of urea: (a) 0.6, (b) 1.2, (c) 2.4, amount of sodium metasilicate: 5.0 g, hydrothermal conditions: $393 \mathrm{~K}, 15 \mathrm{~h}$ 

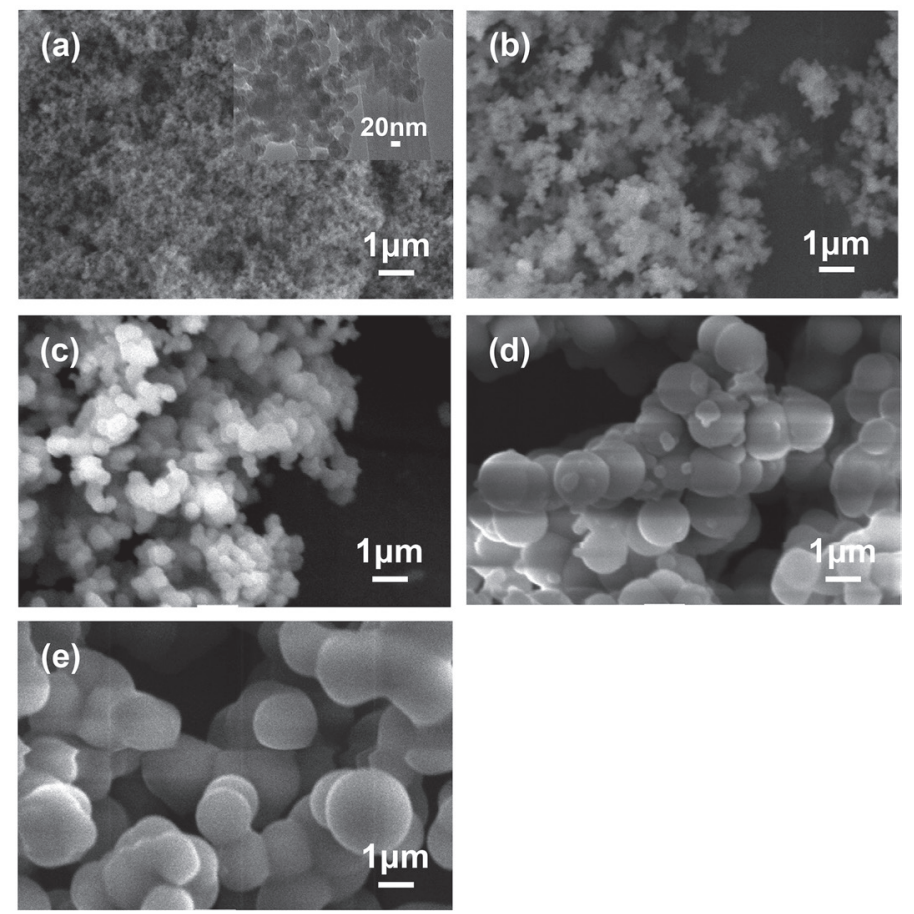

Fig. 2 SEM images of spherical silica particles prepared with different amounts of sodium metasilicate and urea. Amount of sodium metasilicate: (a) 1.0, (b) 2.0, (c) 3.0, (d) 4.0, (e) 5.0 g, amount of urea: (a) 0.24, (b) 0.48, (c) 0.72, (d) 0.96, (e) 1.20 g. Inset of (a): TEM image of the spherical silica particles prepared with $1.0 \mathrm{~g}$ of sodium metasilicate and $0.24 \mathrm{~g}$ of urea. Hydrothermal conditions: $393 \mathrm{~K}, 15 \mathrm{~h}$

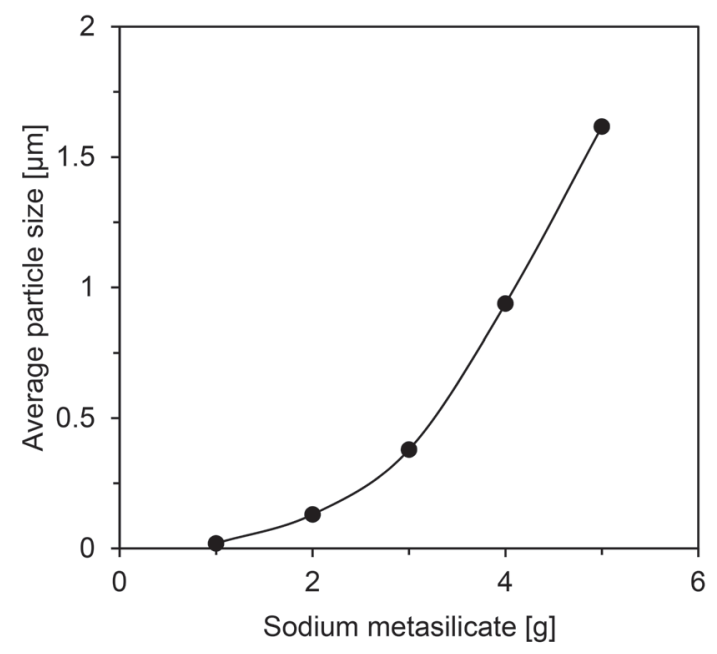

Fig. 3 Influence of the amount of sodium metasilicate on the average particle size of the spherical silica particles (a)
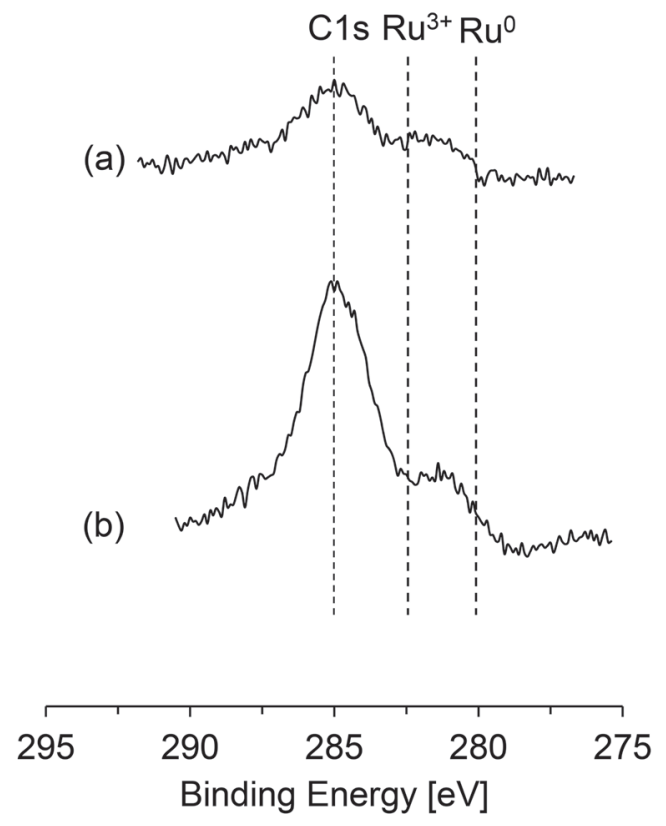

Fig. 4 XPS spectrum of a ruthenium catalyst supported on spherical silica particles prepared by impregnation (a) before and (b) after hydrogenation of carbon dioxide. Ruthenium concentration: $2.0 \times 10^{-2} \mathrm{M}$, particle size of spherical silica particles: $1600 \mathrm{~nm}$ 
concentration used for the preparation of supported catalysts on the ruthenium content of the spherical silica particles. The contents were calculated from results by energy dispersion X-ray spectroscopy. The ruthenium content of the supported catalysts increases with increasing ruthenium concentration used during impregnation. Fig. 6 shows the catalytic activity for the hydrogenation of supercritical carbon dioxide into formic acid over silica supported ruthenium catalysts prepared using different ruthenium concentrations during the impregnation process. This result indicates that the activity is significantly influenced by ruthenium concentration during the impregnation process possibly because the ruthenium concentration influences in dispersion of supported ruthenium species.

In order to understand the tendency in Fig. 6, we investigated immobilization efficiency of ruthenium species

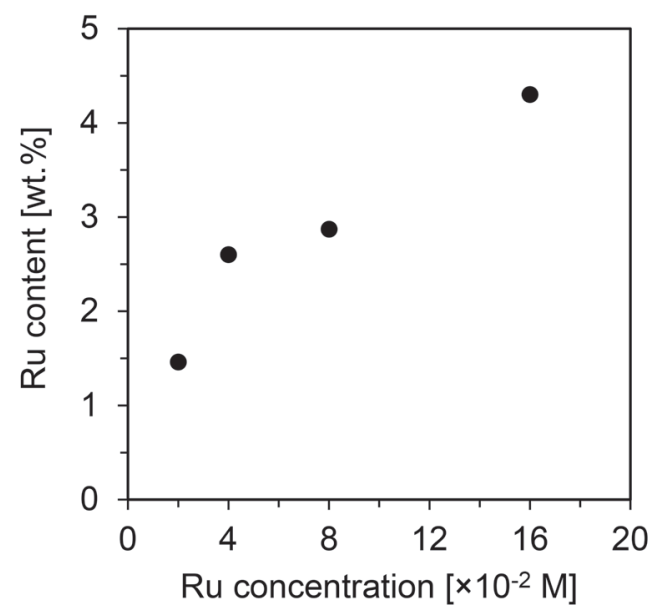

Fig. 5 Dependence of ruthenium content calculated from results of energy dispersion X-ray spectroscopy on ruthenium concentration in the preparation of supported catalysts. Size of silica support: $1600 \mathrm{~nm}$

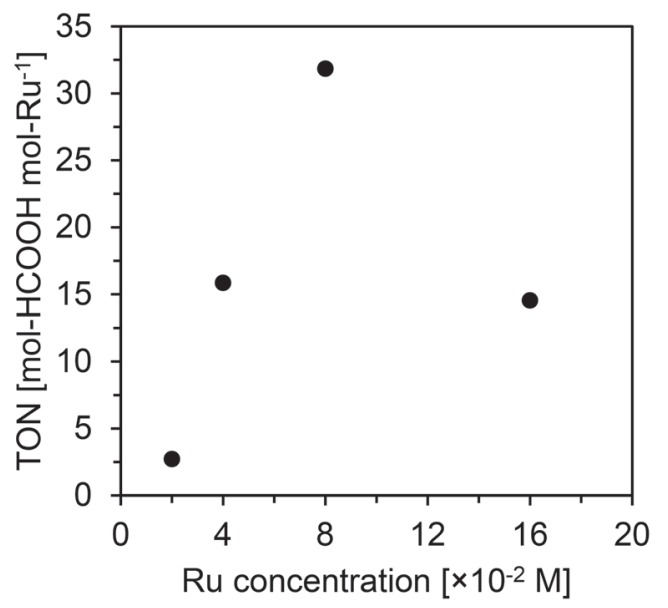

Fig. 6 TON over supported catalysts with different ruthenium contents. Reaction conditions: $\mathrm{H}_{2} / \mathrm{CO}_{2}=5 / 8,13 \mathrm{MPa}$, $353 \mathrm{~K}, 3 \mathrm{~h}$ over the silica supports depending on the particle diameter of the supports. Fig. 7 shows ruthenium content of the supported catalysts. A large amount of ruthenium species (3.9 wt.\%) is supported on the smallest sized silica supports. Similar amount of ruthenium species (2.4-2.9 wt.\%) are supported on the silica supports with the diameter over $130 \mathrm{~nm}$. This result indicates that small silica supports more efficiently immobilize ruthenium species. Based on this result, the activity of the supported ruthenium catalysts using silica supports with diameters of 20 and $1600 \mathrm{~nm}$ were compared. Fig. 8 shows the catalytic activity for hydrogenation of supercritical carbon dioxide to formic acid over the supported catalysts. In the present study, no other products except for formic acid were detected. Both the samples exhibit similar TONs, indicating the size of the silica support does not significantly influence on the activity for the hydrogenation reaction. In order to investigate reusability of the catalyst, the data for the recovery

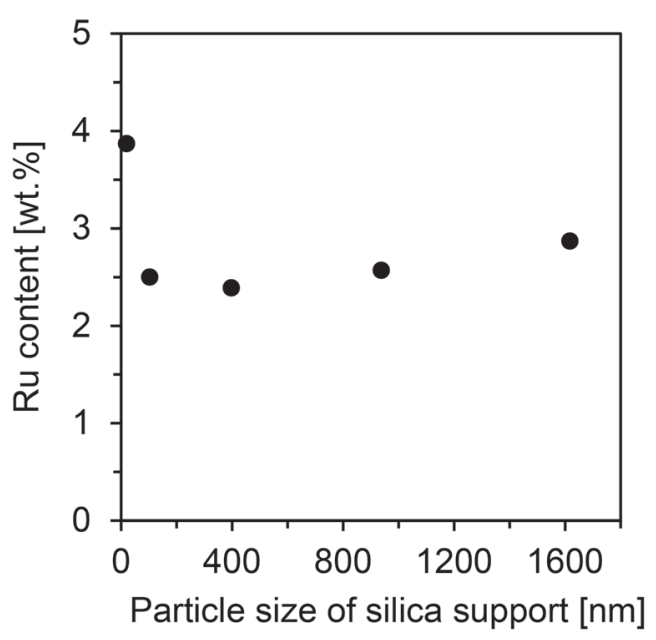

Fig. 7 Dependence of ruthenium content on the average particle size of the silica support

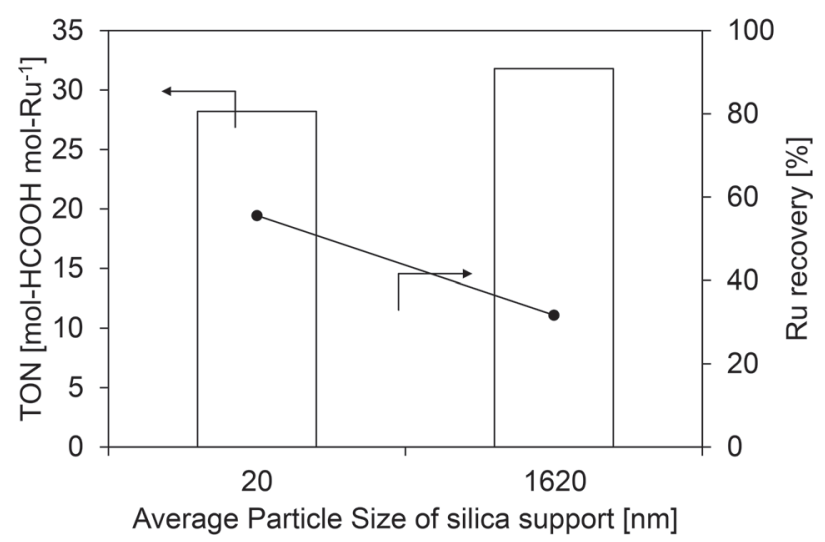

Fig. 8 Catalytic activity for formic acid formation from supercritical carbon dioxide over a ruthenium catalyst supported using spherical silica particles. Reaction conditions: $\mathrm{H}_{2} / \mathrm{CO}_{2}=$ 5 / 8, 13 MPa, 353 K, 3 h 
efficiency of the ruthenium content is also shown. The ruthenium species contained in the supported catalyst with small silica supports is more efficiently recovered compared with that from the catalyst using the larger silica support. From the results shown in Fig. 2(a) and (e), the spherical silica particles with smaller particle size are more closely packed. Void spaces among the particles are small, and the ruthenium content is immobilized in the small void spaces. Thus, the amount of immobilized ruthenium species on the silica support with small particle size after hydrogenation of supercritical carbon dioxide is larger than that on the support with large particle size.

\section{Conclusions}

Silica nanoparticles with a wide range of particle sizes was fabricated from sodium metasilicate solution with urea as the precipitant, and supported ruthenium catalysts on the silica nanoparticles for the hydrogenation of carbon dioxide into formic acid were investigated. Using urea to precipitate silica, spherical silica particles were obtained, and the homogeneity of the particles was improved by adjusting the ratio of sodium metasilicate to urea. Moreover, adjusting the concentrations of sodium metasilicate and urea, the particle size of the spherical silica particles was adjusted between 20 and $1600 \mathrm{~nm}$, and increase with increasing amount of sodium metasilicate and urea. Using the spherical silica supports, supported ruthenium catalysts were prepared by the impregnation method. The amount of supported ruthenium depended on the concentration of ruthenium used in the impregnation process, and the catalytic activity for the hydrogenation of carbon dioxide into formic acid increased with increasing ruthenium content in the supported catalysts. The activity did not significantly depend on the particle size of silica supports, while the amount of ruthenium supported after the reaction compared to the initial amount of ruthenium depended on the particle size of the silica supports, with a higher amount of ruthenium being immobilized on silica supports with smaller particle size.

\section{References}

1) Stöber, W.; Fink, A.; Bohn, E., J. Colloid Interface Sci., 26(1), 62-69 (1968)

2) Zhu, J.; Roggendorf, H., Adv. Mater., 3(10), 522 (1991)

3) Howard, A. G.; Khdary, N. H., Mater. Lett., 61(8-9), 19511954 (2007)

4) Rahman, I. A.; Vejayakumaran, P.; Sipaut, C. S.; Ismail, J.; Bakar, M. A.; Adnan, R.; Chee, C. K., Colloids Surf. A, 294(1-3), 102-110 (2007)

5) Weichold, O.; Tigges, B.; Bertmer, M.; Möller, M., $J$.
Colloid. Interface Sci., 324(1-2), 105-109 (2008)

6) Isobe H.; Utsumi, S.; Yamamoto, K.; Kanoh, H.; Kaneko, K., Langmuir, 21(15): 8042-8047 (2005)

7) Zulfiqar, U.; Subhami, T.; Wilayat Husain, S., J. NonCryst. Solids, 429, 61-69 (2015)

8) Sohn, S.; Kwon, Y.; Kim, Y.; Kim, D., Powder Technol., 142, 136-153 (2004)

9) Ookubo, A.; Ooi, K.; Tomita, T., J. Mater. Sci., 24, 35993604 (1989)

10) Shaw, W. H. R.; Bordeaux, J., J. Am. Chem. Soc., 77, 47294733 (1955)

11) Yoo, J. B.; Yoo, H. J.; Lim, B. W.; Lee, K. H.; Kim, M. H.; Kang, D.; Hur, N. H., ChemSusChem, 5, 2334-2340 (2012)

12) Hemmer, E.; Venkatachalam, N.; Hyodo, H.; Hattori, A.; Ebina, Y.; Kishimoto, H.; Soga, K., Nanoscale, 5, 11339$11361(2013)$

13) Chen, C.; Yee, L. K.; Gong, H.; Zhang, Y.; Xu, R., Nanoscale, 5, 4314-4320 (2013)

14) Di, W.; Velu, S. K. P.; Lascialfari, A.; Liu, C.; Pinna, N. P.; Arosio, P.; Sakka, Y.; Qin, W., J. Mater. Chem., 22, 2064120648 (2012)

15) Xu, Z.; Gao, Y.; Liu, T.; Wang, L.; Bian, S.; Lin, J., J. Mater. Chem., 22, 21695-21703 (2012)

16) Zhang, Z. H.; Chen, L.; Gan, Q. H.; Tian, Q.; Chen, C. L.; Huang, Z. L., Phys. Status. Solidi. A., 210, 378-382 (2013)

17) Qin, H.; Zhang, X.; Liu, H.; Sang, Y.; Wang, J., CrystEngComm., 15, 5076-5081 (2013)

18) Su, L.; Ma, C.; Hou, T.; Han, W., RSC Adv., 3, 19807-19811 (2013)

19) Burattin, P.; Che, M.; Louis, C., J. Phys. Chem. B., 101, 7060-7074 (1997)

20) Khoudiakov, M.; Gupta, M. C.; Deevi, S., Appl. Catal. A, 291, 151-161 (2005)

21) Schwarz, J. A.; Contescu, C.; Contescu, A., Chem. Rev., 95, 477-510 (1995)

22) Peters, M.; Kçhler, B.; Kuckshinrichs, W.; Leitner, W.; Markewitz, P.; Mller, T. E., ChemSusChem, 4, 1216-1240 (2011)

23) Aresta, M.; Dibendetto, A., Dalton Trans., 2975-2992 (2007)

24) Cokoja, M.; Bruckmeier, C.; Rieger, B.; Herrmann, W. A.; Khn, F. E., Angew. Chem. Int. Ed., 50, 8510-8537 (2011)

25) Leitner, W., Angew. Chem. Int. Ed., 34, $2207-2221$ (1995)

26) Jessop, P. G.; Ikariya, T.; Noyori, R., Chem. Rev., 95, 259272 (1995)

27) Federsel, C.; Jackstell, R.; Beller, M., Angew. Chem. Int. Ed., 49, 6254-6257 (2010)

28) Hao, C.; Wang, S.; Li, M.; Kang, L.; Ma, X., Catal. Today, 160, 184-190 (2011)

29) Ying-Min, Y.; Yi-Ping, Z.; Jin-Hua, F.; Xiao-Ming, Z., Chin. 
J. Chem., 23, 977-982 (2005)

30) Jessop, P. G.; Hsiao, P.; Ikariya, T.; Noyori, R., J. Am. Chem. Soc., 118, 344-355 (1996).

31) Fornika, R.; Gkrls, H.; Seemann, B.; Leitner, W. J. J., J. Chem. Soc. Chem. Commun., 1479-1481 (1995)

32) Jessop, P. G.; Joo, F.; Tai, C. C., Coord. Chem. Rev., 248, 2425-2442 (2004)

33) Bi, Q.-Y.; Lin, J.-D.; Liu, Y.-M.; Du, X.-L.; Wang, J.-Q.; He, H.-Y.; Cao, Y., Angew. Chem. Int. Ed., 53, 13583-13587 (2014)

34) Bavykina, A. V.; Goesten, M. G.; Kapteijn, F.; Makkee, M.; Gascon, J., ChemSusChem, 8, 809-812 (2015)
35) Xu, Z.; McNamara, N. D.; Neumann, G. T.; Schneider, W. F.; Hicks, J. C., ChemSusChem, 5, 1769-1771 (2013)

36) Baffert, M.; Maishal, T. K.; Mathey, L.; Copéret, C.; Thieuleux, C., ChemSusChem, 4, 1762-1765 (2011).

37) Preti, D.; Resta, C.; Squarcialupi, S.; Fachinetti, G., Angew. Chem. Int. Ed., 50, 12551-12554 (2011)

38) Li, J. G.; Li, X. D.; Sun, X. D.; Ikegami, T.; Ishigaki, T., Chem. Mater., 20, 2274-2281 (2008)

39) Wang, W.; Guo, S.; Lee, I.; Ahmed, K.; Zhong, J.; Favors, Z.; Zaera, F.; Ozkan, M.; Ozkan, C. S., Sci. Report., 4, 1-9 (2014) 